\title{
Correction to: Production of eco-friendly concrete incorporating rice husk ash and polypropylene fibres
}

\author{
Muhammad Jaffar Memon ${ }^{1} \cdot$ Ashfaque Ahmed Jhatial ${ }^{1}$ (1) Ali Murtaza ${ }^{2} \cdot$ Muhammad Saleem Raza $^{2} \cdot$ \\ Karim Bux Phulpoto ${ }^{1}$
}

Published online: 5 April 2021

(C) Springer-Verlag GmbH Germany, part of Springer Nature 2021

\section{Correction to: Environmental Science and Pollution Research} https://doi.org/10.1007/s11356-021-13418-3

The correct image of figure 4 is shown in this paper

The online version of the original article can be found at https://doi.org/ $10.1007 / \mathrm{s} 11356-021-13418-3$

Ashfaque Ahmed Jhatial

ashfaqueahmed@muetkhp.edu.pk

Muhammad Jaffar Memon

jaffar.memon@muetkhp.edu.pk

Ali Murtaza

ali.murtaza@faculty.muet.edu.pk

Muhammad Saleem Raza

saleemraza43@yahoo.com

Karim Bux Phulpoto

kareembuxbux80@gmail.com

1 Department of Civil Engineering, Mehran University of Engineering and Technology, Shaheed Zulfiqar Ali Bhutto Campus, Khairpur Mirs', Sindh 66020, Pakistan

2 Department of Civil Engineering, Mehran University of Engineering and Technology, Jamshoro, Sindh 76062, Pakistan

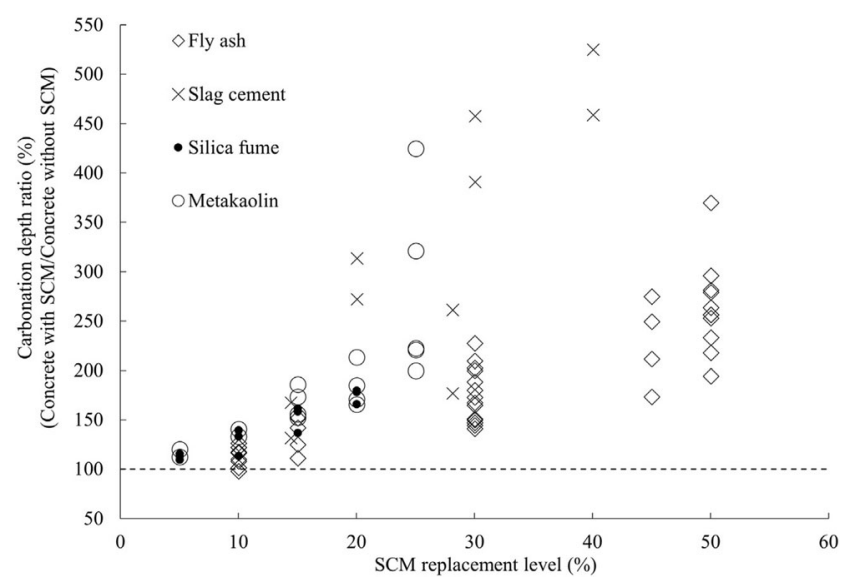

Fig. 4 Influence of SCM replacement levels on the concrete carbonation depth (Panesar 2019)

Publisher's note Springer Nature remains neutral with regard to jurisdictional claims in published maps and institutional affiliations. 